\title{
Sea surface height variability in the North East Atlantic from satellite altimetry
}

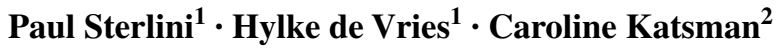

Received: 4 June 2015 / Accepted: 28 October 2015 / Published online: 11 November 2015

(C) The Author(s) 2015. This article is published with open access at Springerlink.com

\begin{abstract}
Data from 21 years of satellite altimeter measurements are used to identify and understand the major contributing components of sea surface height variability (SSV) on monthly time-scales in the North East Atlantic. A number of SSV drivers is considered, which are categorised into two groups; local (wind and sea surface temperature) and remote (sea level pressure and the North Atlantic oscillation index). A multiple linear regression model is constructed to model the SSV for a specific target area in the North Sea basin. Cross-correlations between candidate regressors potentially lead to ambiguity in the interpretation of the results. We therefore use an objective hierarchical selection method based on variance inflation factors to select the optimal number of regressors for the target area and accept these into the regression model if they can be associated to SSV through a direct underlying physical forcing mechanism. Results show that a region of high SSV exists off the west coast of Denmark and that it can be represented well with a regression model that uses local wind, sea surface temperature and sea level pressure as primary regressors. The regression model developed here helps to understand sea level change in the North East Atlantic. The methodology is generalised and easily applied to other regions.
\end{abstract}

Keywords Sea surface variability · Sea level change · North East Atlantic · North Sea

Paul Sterlini

Paul.Sterlini@knmi.nl

1 Royal Netherlands Meteorological Institute, de Bilt, The Netherlands

2 TU Delft, Delft, The Netherlands

\section{Introduction}

The assessment of temporal changes in global mean sea level (GMSL) is an area of intense study (e.g. Church and White 2006, 2011; Cazenave et al. 2014; Slangen et al. 2014; Haigh et al. 2014). Tide gauge observations indicate that GMSL rose in the order of $1.7 \pm 0.2 \mathrm{~mm} /$ year during the twentieth century (Church et al. 2013) however the rate of local sea level rise may differ substantially from the global rate due to, for example, surface winds, ocean currents, spatially varying ocean heat uptake, spatial variations in salinity and variations in the Earth's gravity field (Chambers et al. 2002; Katsman et al. 2008; Church et al. 2013).

In addition to these spatial variations, sea level change is also subject to significant fluctuations in time. The sea surface height ( $\mathrm{SSH}$ ) is in dynamic equilibrium with a number of forcing mechanisms each operating on differing spatial scales and within differing time scales. The variation of SSH in time (sea surface height variability; SSV) is therefore a superimposition of a many SSH variation signals arising from a number of forcing factors. Indeed, there is evidence that SSV operates on a huge range of time scales ranging from the sub-day scale to decades and even longer (e.g. Sturges and Douglas 2011; Calafat et al. 2012; Dangendorf et al. 2014a). Understanding SSV and its forcing mechanisms is a prerequisite to eventually remove its contribution from the SSH time series when conducting $\mathrm{SSH}$ trend analyses or validating future projections of sea level change.

This paper aims to examine/quantify the SSV in the North East Atlantic (NEA) with a particular focus on the South East North Sea and to identify its underlying drivers.

Studies in this region have identified a number of forcing mechanisms of SSV for the NEA with some of them being 
linked to the NAO, especially during winter (Tsimplis and Shaw 2008). Atmospheric forcing, in terms of barotropic wind and pressure effects, has been shown to be a dominant forcing factor (Wakelin et al. 2003; Woolf et al. 2003; Yan et al. 2004). However, these barotropic influences seem to diminish after a few years (Dangendorf et al. 2013). On longer timescales baroclinic adjustment processes become more important (Chen et al. 2014). Recent studies, for instance, suggest that on longer timescales there is a largescale coherent response of the coastal waters to longshore winds in the form of propagating boundary waves in the NEA (Sturges and Douglas 2011; Calafat et al. 2012, 2013; Dangendorf et al. 2014a). Changes in ocean heat content also influence regional SSV (Bilbao et al. 2015) as it leads to expansion or contraction of the water column, affects ocean circulation and density patterns as well as the melting of (land) ice (Gornitz et al. 1982).

Much work investigating the mean sea level and SSV in the North Sea has used tide gauge data as data records span several decades and in some cases centuries (e.g. Yan et al. 2004; Woodworth et al. 2010; Calafat et al. 2012, 2013; Richter et al. 2012; Calafat and Chambers 2013; Dangendorf et al. 2014a). Tide gauge studies have provided a wealth of detailed information relating to SSV at specific stations which are usually situated coastally and inherently limited in spatial coverage. A further limitation of tide gauge data however is that they are not a priori representative of open ocean processes or mechanisms that affect SSH from a remote location. Supplementary data sets such as altimetry, steric heights from models or assumptions from consistency between tide gauge locations have been used to augment tide gauge data in order to connect them to the spatial scale and make assumptions relating to processes that operate over a spatial domain (Chambers et al. 2002; Dangendorf et al. 2014a). Indeed, spatial signals have been numerically modelled and removed from tide gauge data from which there is otherwise no spatial information (Marcos and Tsimplis 2007). In this last study the atmospheric component of SSV was quantified and removed from tide gauge data through the use of a 2D barotropic ocean model. Both barotropic and baroclinic models have been used extensively to assess linkages between climate indices or physical processes and their effect on the North Sea (e.g. Wakelin et al. 2003; Calafat et al. 2012; Chen et al. 2014) or to provide information on the sea level itself (e.g. Dangendorf et al. 2014a; Chen et al. 2014). In these cases, model input conditions can be tuned to make these models into powerful tools to test the response of the ocean to any number of parameters.

To identify and isolate the primary natural modes of SSV in the NEA we use satellite altimetry data. This allows a spatial view of the SSV in the region, and an examination into identifying drivers that may operate over the area, both locally and those which act remotely. In this way we cover the response of SSH to forcing mechanisms that operate on different spatial scales. Here we define SSV as the standard deviation of the monthly anomalies of observed SSH with respect to the deseasoned and linearly untrended SSH time series over the 21 years of observation.

Using altimetry for SSV studies is not without its drawbacks; where it offers spatial information, the length of time series is limited to that of the satellite altimetry era at best. SSV studies using altimetry are therefore limited to short term variability $(<21$ years $)$ and SLA response to mechanisms which act in these time scales because it is difficult to separate long-term signals from decadal-scale variability.

Another motivation for the use of altimetry is that it can help us understand how and to which extent oceanic signals are transmitted through the shelf to the coast. Exploring open ocean variability is important, but linking such variability to coastal sea level changes is crucial as the coastal zone is where the effects of climate change are really felt. However, we are cautious with altimeter data in coastal regions due to a degradation of data, for example, due to the corruption of the altimeter instrument wave forms by land and inaccurate geophysical corrections.

Our approach is to model observed SSV with a linear regression model (LRM) to test potential forcing mechanisms as regressors which have been identified from a correlation analysis that looks at covariance of those drivers with the SSH and with each other. A similar technique using LRMs has also been used by Calafat and Chambers (2013) and Dangendorf et al. (2013, 2014a) to address internal climate variability using data from tide gauges in the North Sea.

One of the difficulties is that there is interdependence between some of the proposed (atmospheric) forcing mechanisms. Additionally there are substantial decorrelation time and spatial scales so there is a real possibility of overfitting if too many regressors are included in the model. This issue can be partially avoided with the use of climate indices that bring together many parameters and represent them in a single index. Alternative approaches are to use stepwise models with a significance level based on red noise models, or to identify and (where possible) isolate a number of primary or key forcing mechanisms at the top of the forcing process chain and limit the number of regressors used in the LRM.

The paper is subdivided as follows. Section 2 describes the methodology in determining the primary SSV drivers, with data sources given in Sect. 3. Observed SSV is discussed in Sect. 4; results and an insight into understanding the processes driving the SSV is discussed in Sects. 5 and 6. Finally, conclusions are drawn in Sect. 7. 


\section{Methodology}

\subsection{Areas of interest}

The primary area of interest for this study is a region off the coast of Denmark bounded by $5^{\circ} \mathrm{E}-7^{\circ} \mathrm{E}, 54^{\circ} \mathrm{N}-56^{\circ} \mathrm{N}$. This region of the North Sea, which we refer to as the DaNS (Danish North Sea) area, is characterised by particularly high SSV as shown in Fig. 1 and detailed in Sect. 4. In order to put the DaNS area into perspective the SSV structure for the larger domain of the NEA will also be discussed.

\subsection{Parameters affecting SSV}

SSV is forced by driving mechanisms that act in different time and spatial scales. Regionally the number, role and relative importance of these factors can vary as it will depend on local considerations such as basin shape, bathymetry and the vicinity of the coastal boundary. Note that at this stage we assume no a priori knowledge of which factors
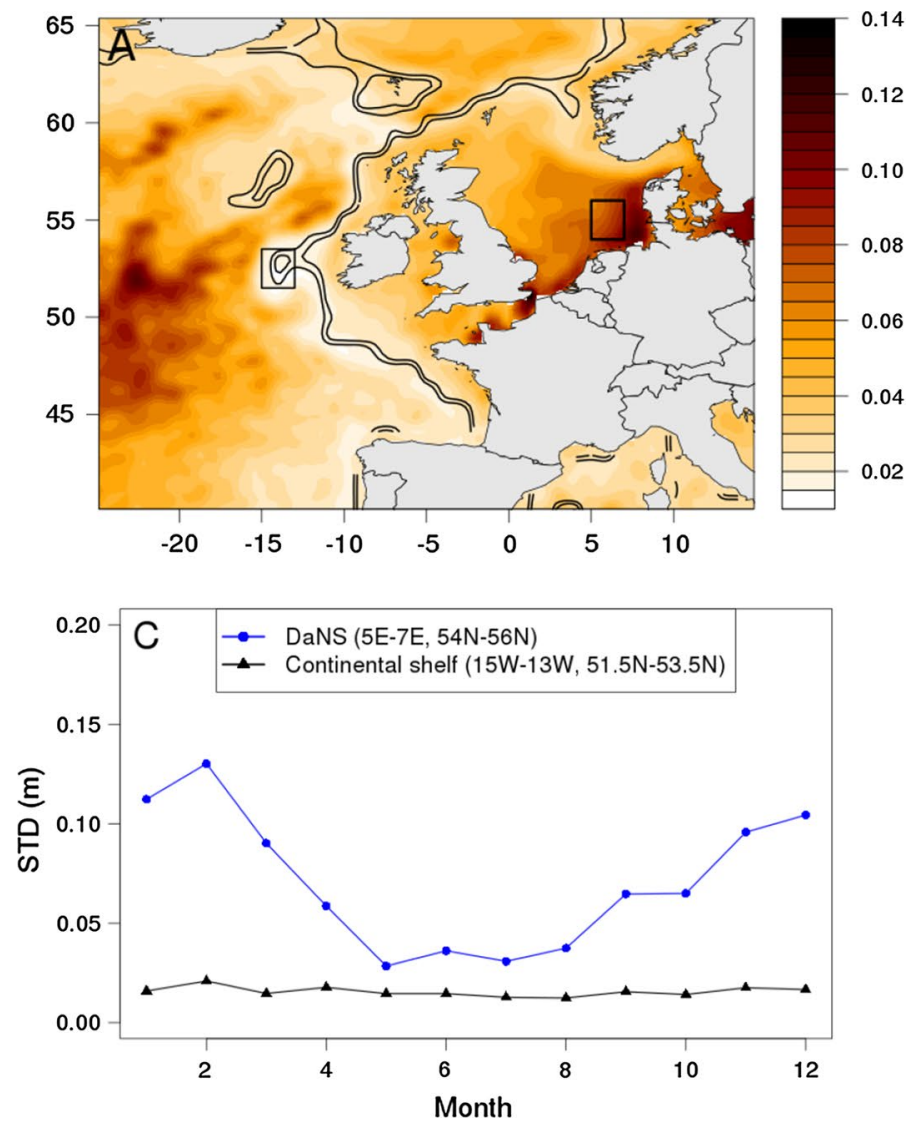

Fig. 1 a Observed SSV (m) in the North East Atlantic. The black contours show the 300 and $500 \mathrm{~m}$ bathymetry isolines. b Monthly SLA for the DaNS area. c Annual cycle of SSV for the DaNS area in may play an important role in affecting SLA at a particular location, and we effectively build a list of potential descriptive parameters from which relationships may be found at a later stage.

In this paper we categorise the parameters into two groups depending on their spatial scale: local and remote:

- Local As local factors we consider zonal and meridional wind at $10 \mathrm{~m}$ height (u10, v10) and sea surface temperature (SST). Wind speed (WS) and surface wind stress (zonal and meridional; UST and VST respectively) are also tested for completeness. Detailed studies targeted at a specific coastline have been shown to benefit from using rotated perpendicular components of wind speed to maximise the cross-shore component (de Ronde et al. 2014). However, since our aim is to examine SSV more generally and not only near the coast, rotation of the wind field is not used and we simply use both zonal and meridional wind.

- Remote The North Atlantic oscillation (NAO) is included as a far field parameter potentially relevant to
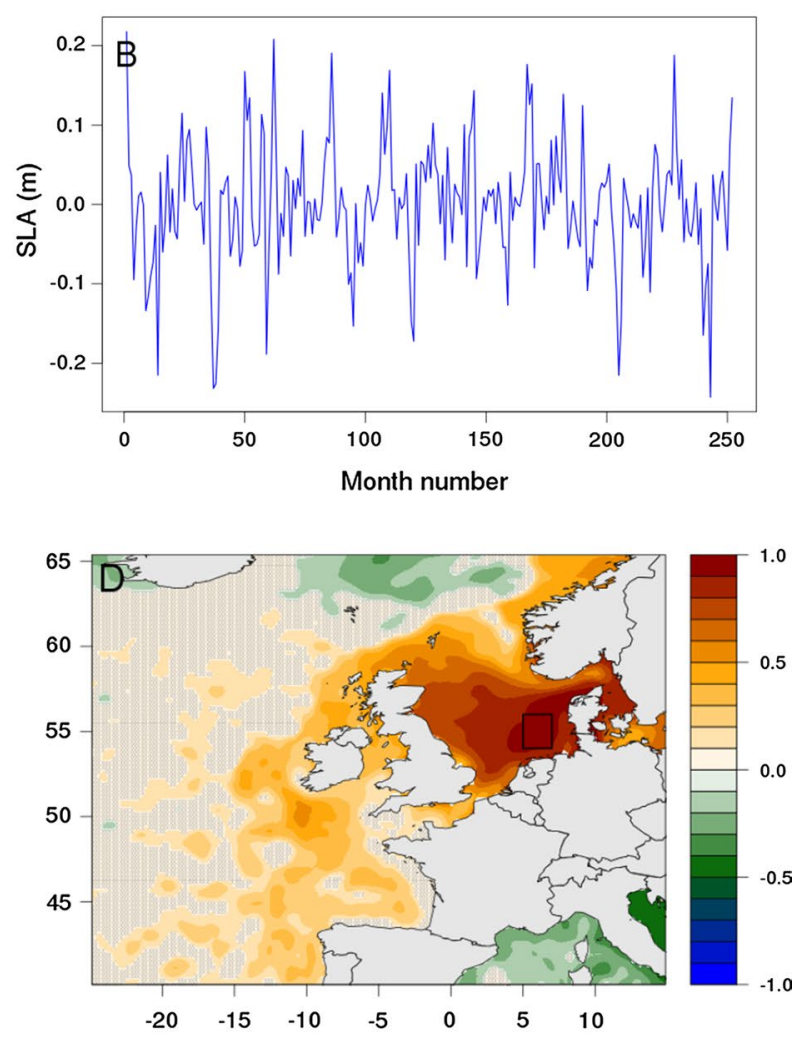

the North Sea and a location near the continental shelf edge, off the west coast of Ireland (see legend and Panel a). d Correlation between box-average SLA (DaNS area) and the local SLA elsewhere 
the DaNS area. We also test with atmospheric pressure at sea level (SLP) as an indication of a pressure gradient which acts remotely.

Additional components that can (of course) be added to this list of potential SSV drivers. Generally this will be dependent upon the specific region and for areas other than the North Sea we would probably need to consider drivers that are more specifically related to those regions. For example, in our analysis of the SSV in the Indonesian archipelago region (not presented), the NINO 3.4 index and the Pacific Decadal Oscillation index were found to be significant in describing the SSV.

A first order estimate of the potential relevance of a candidate SSV driver is provided by its correlation with SLA in the desired target area, though it is noted that a high correlation does not necessarily imply a physical or dynamical relation between the driver and the SLA.

\subsection{Linear regression model (LRM)}

A multiple LRM is constructed using (a subset of) the drivers above to test how well they can describe local SSV. The most general LRM formula is:

$\operatorname{ssh}_{l o c}(x, y, t)=\sum_{i} \alpha_{i}(x, y) F_{i}(x, y, t)+\epsilon_{l o c}(x, y, t)$

where $\alpha_{i}(x, y)$ indicates the regression coefficients (determined locally), $F_{i}(x, y, t)$ the driving mechanisms (not necessarily local), and $\epsilon_{l o c}(x, y, t)$ a local residual error. The inclusion of auto-regressive terms $\left(\operatorname{ssh}_{l o c}(x, y, t-j), j=1,2, \ldots\right)$ in the right hand side of the above equation is not considered at this stage, although it is known that memory is generally important for SSV (Dangendorf et al. 2014b).

The inclusion or exclusion of the forcing mechanisms identified above will lead to a reconstructed SLA with various degrees of fit to the observed sea levels. It is assumed that higher correlation between reconstructed and observed sea level indicates a better representation of the variability described by the selected combination of forcing mechanisms. Following Calafat et al. (2013) we also test for explained variance which takes both variability and the differences in the amplitude between the observed and modelled sea surface into account. Explained variance is computed as:

$E V_{i}=\frac{\operatorname{var}\left(y-y_{i}\right)}{\operatorname{var}(y)}$

where $y$ denotes SLA and $y_{i}$ denotes the reconstructed SLA, or simply a particular component. Because of the relatively short time-span of the altimeter data (21 years) we use the entire period for both constructing and testing our linear statistical model. In addition we have tested the robustness of these results by using only the first third of the data to train the model and testing it on the full data set.

\subsection{Cross-correlations and multi-collinearity}

A fundamental problem encountered in any multiple linear regression approach is that the candidate driver components (i.e. the possible regressors) may not be statistically independent from each other. This inter-relation between components not only obscures the interpretation of the results (especially the partitioning) but also inflates their confidence estimates. In statistical literature this problem is known as multi-collinearity.

Here we use a simple and objective method to assess the relevance of a particular regressor in a statistical model. This method is based on the variance inflation factor (VIF). The VIF of a particular regressor in a regression model measures to what extent this regressor can be understood from a linear combination of the other regressors. For a given regression model with $F_{j}, j=1,2, \ldots n$ regressors, the VIF of component $F_{i}$ is given by:

$V I F_{i}=\frac{1}{1-R_{i}^{2}}$

where $R_{i}^{2}$ is the squared correlation between $X_{i}$ and $X_{f i t, i}$ with $X_{i}=X_{f i t, i}+\epsilon$ and $X_{f i t, i}=c_{0}+\sum_{j \neq i} \beta_{j} X_{j}$. A component is completely independent from the other components if its VIF is unity. There is however no upper-bound to the VIF.

Based on VIF analysis a straightforward stepwise regressor selection method is employed. Starting with all regressors, in the first round of selection we compute all VIF factors and remove the regressor with the highest VIF if it is larger than a predefined threshold of 2. From Eq. 3 this corresponds to a correlation of 0.5 , meaning that if at least $25 \%$ of a regressor's variance can be explained by the remaining regressors, it will be discarded. After this regressor has been removed from the model the VIF factors are determined again, isolating a second possibly "redundant" regressor. This procedure continues until all remaining VIF factors are below the desired threshold. This stepwise approach means that ultimately we end up with a number of drivers that can describe other parameters but which cannot themselves be described and are statistically distinct from each other ( $\mathrm{R}$ is less than 0.5$)$. This facilitates subsequent interpretation.

It is important to note that the independence of data does not mean that it is a relevant descriptor or forcing mechanism for a change in sea level. Connection of a data set with an underlying physical process is therefore of paramount importance and ultimately data to be included or excluded in the LRM is subject to such a physical motivation. 
Ideally, the hierarchical selection is carried out locally because different local areas may experience very different driving mechanisms. This is true for the North Sea where Chen et al. (2014) and Dangendorf et al. (2014a) showed that the it can be divided into different regimes which are dominated by either wind or SLP. This consideration also holds for the area over which spatial averaging is carried out (SSV of the GMSL encounters different drivers than local sea level of the Bay of Bengal, for example). However, when representing results graphically on a map it may destroy their spatial coherence if different components are used in nearby locations. We therefore apply the VIF-based method to our target area (discussed below) and subsequently use those components for the entire domain.

\section{Data and pre-processing}

Daily gridded mean sea level anomaly (SLA) data for the NEA area were downloaded from AVISO for the period 1993-2013 at $0.25^{\circ}$ spatial resolution. The "all-sat-merged" product is used, to which standard corrections, including the Dynamic Atmospheric Correction, have been applied as documented in the AVISO Handbook (AVISO 2014). Daily zonal and meridional wind speed at $10 \mathrm{~m}$ height ( $\mathrm{u} 10$ and v10 respectively), atmospheric pressure at sea level (SLP) and sea surface temperature (SST) were downloaded from the Global Reanalysis ERA-Interim dataset (Dee et al. 2011). In using SST we assume that the surface layer in shallow waters is well mixed. This assumption is validated through a comparison between the SST field and vertical mean temperature (VMT) data based on 3D ocean temperature from the ORAS4 ocean reanalysis model (ECMWF 2015). VMT is not directly used here as the product assimilates altimetric SLA (ECMWF $2015)$ so is excluded for reasons of consistency. ICOADS $2^{\circ}$ enhanced surface wind stress was downloaded from NOAA/ OAR/ESRL PSD (2015) (meridional, UST; zonal, VST). Monthly values of the North Atlantic oscillation index (NAO) were downloaded from CRU/UEA (2014) through the KNMI Climate Explorer website (www.climexp.knmi.nl).

To remove the trend associated with the changing mass of the oceans we subtract the GMSL from the SLA field. Since this also removes the global mean, only processes which act regionally in the time series remain. Only monthly mean fields are used to remove temporal high-frequency variability in all fields. In addition we subtract the multi-year monthly means over the period 1993-2013 for all fields to remove the basic seasonal cycle.

Low frequency signals can alias as a long term trend in a relatively short altimetry record of 21 years. Since regression models are unable to separate these decadal fluctuations from long term trends, stationarity of the underlying time series is required. To address this we linearly detrend all time series. However, Frankcombe et al. (2014) demonstrated that removing linear trends based on short term data may lead to biases. We therefore test for the robustness of the regression coefficients used in the LRM. Thus our study is based on the SSV of detrended monthly anomaly fields.

\section{Observed regional SSV}

Figure 1a shows the mean SSV pattern by means of the standard deviation of the monthly SLA over 21 years for the NEA. The SSV pattern is rich in structure and characterised by large regional differences. Strong SSV is seen in the North Sea with a maximum of around $14 \mathrm{~cm}$ off the west coast of Denmark (DaNS area). There are isolated 'hot spots' of high SSV in the English Channel, as well as a diffuse region of high SSV in the Atlantic Ocean that coincides with the tail end of the Gulf Stream. Approximate bathymetry is also shown and seems to indicate areas of low variability near the edges of the continental shelves. The monthly time-series of SLA in the DaNS region is shown in Fig. $1 \mathrm{~b}$.

In the construction of the monthly SLA values we removed the mean seasonal cycle. However the SSV of the SLA contains a seasonal cycle; the mean standard deviation of all SLA values over the 21 year period for each month are shown in Fig. 1c for two subregions: the DaNS area and a region at the continental shelf edge off the west coast of Ireland. Both regions are indicated in Fig. 1a. For the DaNS area the variability peaks in the winter months; we will see in the next section that this is consistent with a variability forcing dominated by wind. Near the continental shelf edge the SSV remains rather low throughout the year.

Figure 1a, c show that SLA displays regional behaviour with marked differences. However, this does not imply that there is no spatial coherence within the SLA field. On the contrary, certain areas display a surprisingly high degree of spatial coherence, especially those over shallow continental shelf seas such as the North Sea. As the DaNS area in the North Sea is our area of interest (Fig. 1) it is instructive to reveal this coherence with respect to that particular region.

Figure 1d shows the correlation between SLA in the DaNS area and local SLA elsewhere. As expected this correlation is near unity in the vicinity of the DaNS box but it remains surprisingly high in much of the entire North Sea basin before rapidly becoming insignificant off the continental shelf. This is an indication of strong spatial coherence over the entire North Sea shelf. This spatial coherence is a common feature of (shallow) shelf seas worldwide (Hughes and Meredith 2006). However, we note here that the coherence that is clearly visible on the shelf does not extend into the English Channel which suggests that this region experiences different processes in driving SSV than in the DaNS region. This may be due to differences in water depth, 

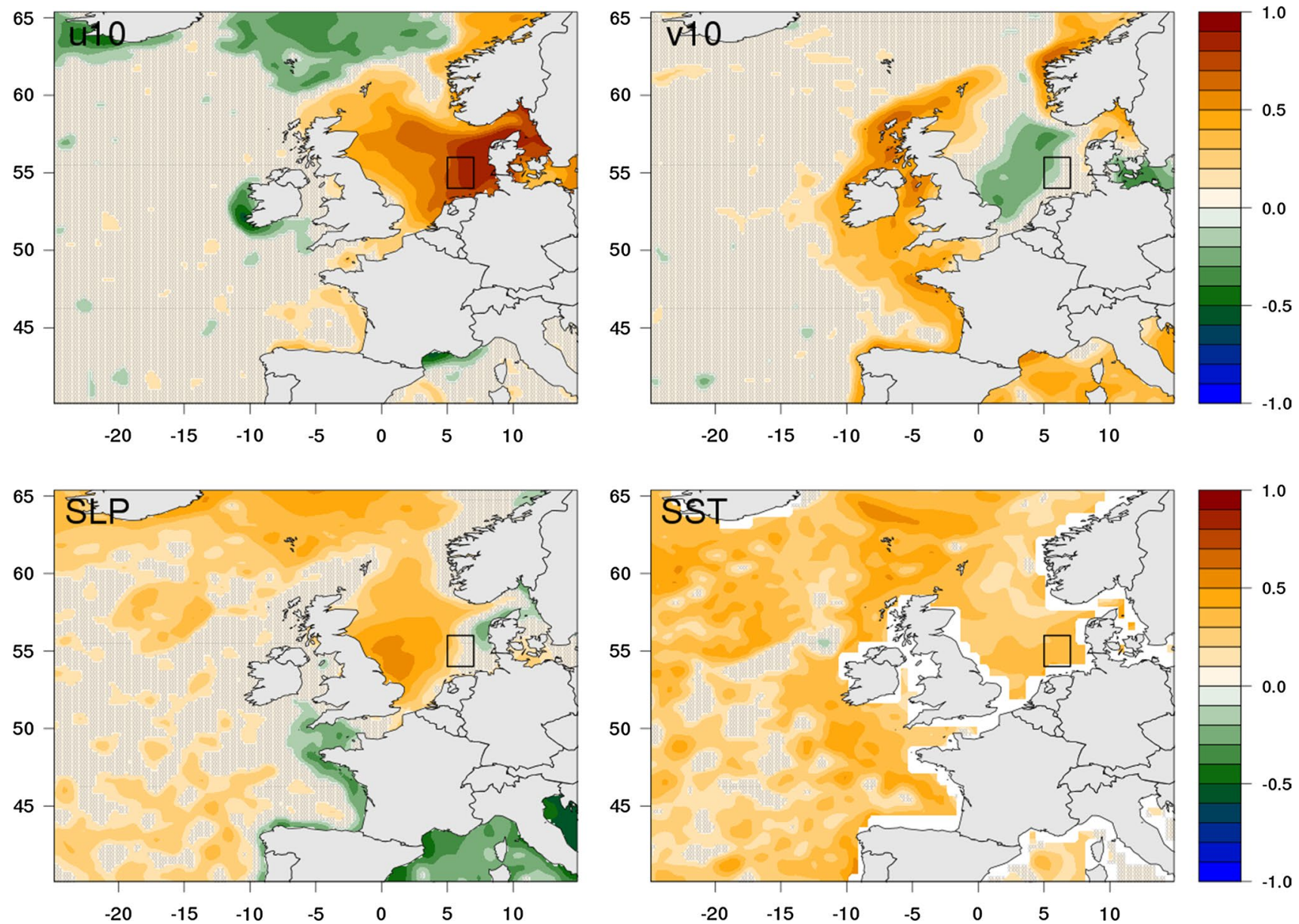

Fig. 2 Correlation maps between local SLA and field parameters; u10 (upper left), v10 (upper right), SLP (lower left) and SST (lower right). Statistical significance of the correlations has been assessed on

the basis of the Fisher z-transform. Crossed where non-significant at $95 \%$ confidence level

coastal geometry and local meteorology, and highlights the spatial variation in the predominant causes of SSV.

\section{Understanding regional SSV}

A picture emerges from the previous section of a locally substantially different SSV that might be explained from a combination of different driving mechanisms. In Sect. 2 we explained the methodology that will be used to determine what those driving mechanisms might be. Here we present and explain the results from this analysis with attention to the processes acting behind the drivers, where applicable.

\subsection{Local field parameters}

Local correlation maps for SLA with u10, v10, SLP and SST are shown in Fig. 2. The figure shows that there is a clear spatial structure in the correlation patterns in the
North Sea for the wind components (and SLP which partly drives the wind). The wind components $\mathrm{u} 10$ and $\mathrm{v} 10$ are coupled and on monthly time-scales largely follow the atmospheric pressure distribution. However, which of the two components play the most significant role in driving SLA in a given location is strongly dependent on the coastal geometry.

Correlations of SLA with zonal wind speed (u10, eastward wind defined positive) are very high and positive (maximum values above 0.9) in most of the North Sea basin (and extending along the Norwegian coast line). The correlation between u10 and SLA decreases as we go further north and off the continental shelf. This near-coastal zone influence of the wind on SLA is found throughout the world but is extremely clear in the North Sea. Negative correlations are found off the north coast of Scotland and along the west of Ireland.

The structure of the correlation map with meridional wind speed ( $\mathrm{v} 10$, northward wind defined positive) is very 
Table 1 Correlation between SLA and possible field parameters for the DaNS area

\begin{tabular}{llllllll}
\hline Field driver & u10 & v10 & UST & VST & WS & SST & SLP \\
\hline SLA (DaNS) & 0.84 & -0.13 & 0.84 & NS & 0.37 & 0.36 & NS \\
\hline
\end{tabular}

NS not significant at the $95 \%$ confidence level different from that of $\mathrm{u} 10$. Positive correlations between SLA and v10 are found off the west coast of the UK and off the Norwegian coast, and a region of negative correlation is evident against the east coast of the UK. Respective correlation maps with UST and VST (not shown) show similar spatial patterns as with wind speed, but exhibit a more gridded structure due to the lower resolution of the surface wind stress data than the SLA.

The overall picture of the SLA response to wind forcing is one of Ekman transport, and is in line with results found by Dangendorf et al. (2014a) who used tide gauge records to assess the barotropic response of the North Sea to atmospheric forcing; longshore components of wind dominate the SLA everywhere along the coast in the North Sea basin. Specifically, Ekman transport in the open ocean is generated by the northward winds which results in a net movement of water towards the east and against the UK coast. Similarly, Ekman transport within the North Sea basin is generated from eastward winds leading to a southward movement of water against the Dutch and German coastlines. In these cases the coastlines induce a convergence of water and a subsequent SLA response through mass conservation. This response of the SLA to wind appears to be largely confined to the shallow seas on the continental shelf and therefore suggests that wind is the primary forcing mechanism of SSV in the North Sea.

The correlation pattern of SLA with SLP shows high positive values off the east coast of the UK and to the north of Scotland and weakly negative values to the west of France and off the Danish coast. This pattern is broadly similar to the inferred correlation patterns seen in model simulations performed by Chen et al. (2014) who tested for the IB effect induced by local SLP. However, we note that the correlation seen in Fig. 2 exists even though the inverse barometer correction has been applied to the altimeter data. This implies that whilst the SLP does not represent an actual physical connection with SLA, the correlations seen here may be due to the SLP acting though other (non local) forcing factors such as wind. This is explored in more detail in Sect. 6.3.

The final local driver we consider is SST which is used here as a measure of the heat content of the local well mixed waters. We therefore expect to find increasing sea levels with increasing values of SST due to thermal expansion of the water column. The spatial pattern of the correlation between SLA and SST seen in Fig. 2 is generally positive with high values folding around southern Iceland towards Scotland. This positive correlation with SST confirms our expectation that sea level is generally higher with warmer SSTs.

\subsection{The DaNS area (1): local drivers and remote forcing}

We now provide further detail for the DaNS area. Table 1 lists the correlation coefficients between monthly SLA over the DaNS area and the tested field drivers. Wind speed (WS) and zonal and meridional wind stress (UST and VST respectively) are included for completeness. Of the tested local SSV drivers, zonal wind clearly stands out as being most important, consistent with Fig. 2.

Correlation between SLA and SLP in the DaNS is not significant (also see Fig. 3f). As the local SLA response to local SLP is the IB effect (Dangendorf et al. 2014a) this hints that the DAC correction (including IB) applied to the altimetry data is correct in the DaNS region as it removes the wind and pressure effects for periods below 20 days and the IB effect for periods larger than 30 days (AVISO 2014).

Up to now we have tested only the correlation between the SLA and a driver (for example, the wind) at the same location. However, especially in near coastal zones where bathymetry, coastline geometry and other effects may be important, it can be argued that one should relax this condition of examining colocated SLA and driver fields. In this section we therefore expand the colocated correlation analysis to a local SLA (box average over the DaNS area) to a driver over a field with the aim of ascertaining whether there is a spatial pattern in forcing SSV by drivers from a remote location.

Figure 3 shows the correlation between the box average SLA over the DaNS area and fields of wind parameters, SLP and SST. It is clear that the influence of $\mathrm{u} 10$ on SLA in the DaNS area is a large-scale pattern. In fact, the highest correlations are found in an area to the North of the DaNS. Negative correlations up to -0.6 also exist between $\mathrm{u} 10$ and SLA in the DaNS off the South of Spain. This negative correlation comes about because the wind field itself is forced by large-scale pressure differences. Indeed, a similar but displaced correlation structure is seen in the panel showing correlation with SLP (lower left). Note that the SLP correlation structure supports the predominance of eastward wind and its effect on SLA in the DaNS region, though in itself does not have a direct role in driving local SLA (Wakelin et al. 2003; Dangendorf et al. 2013). 

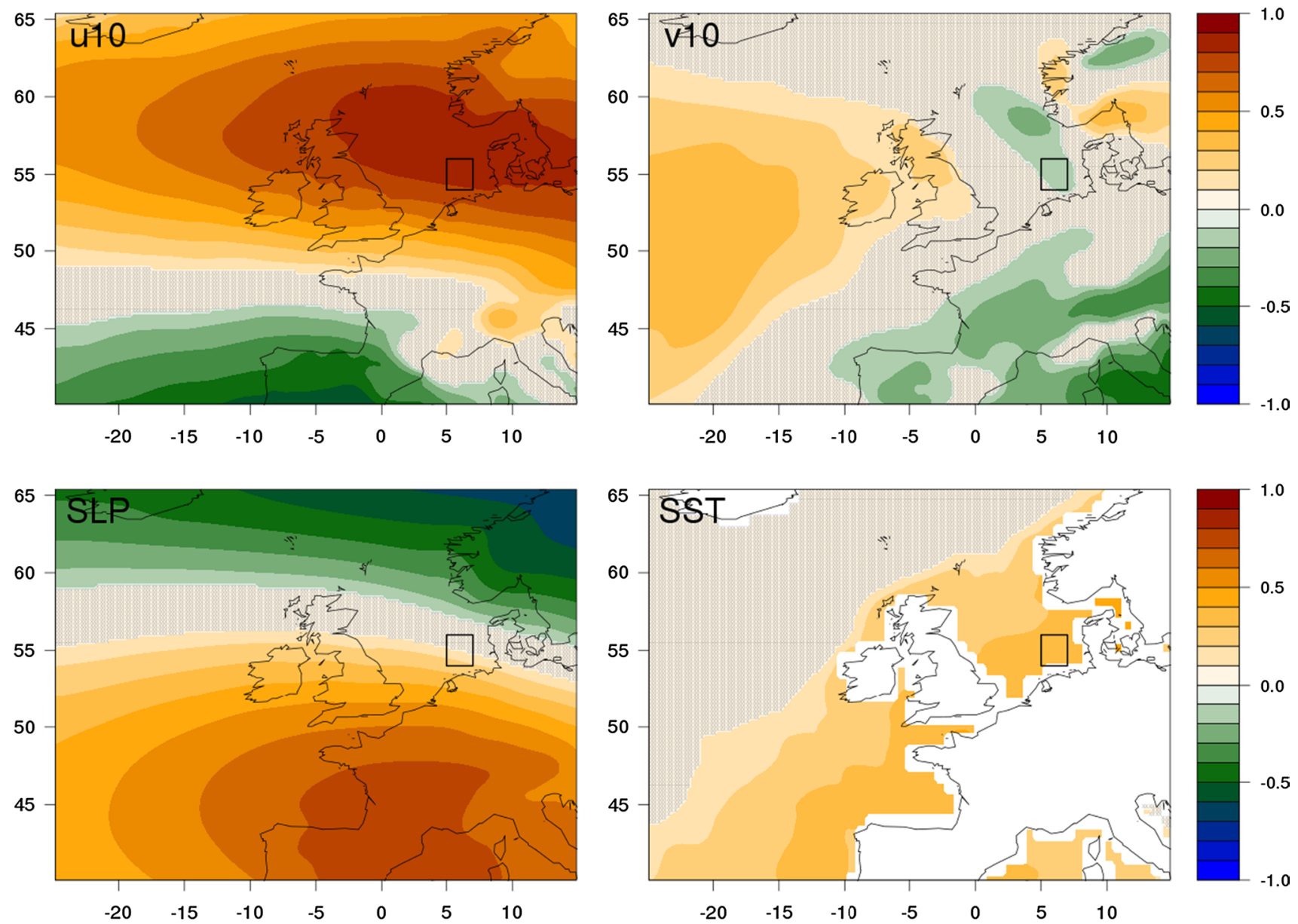

Fig. 3 Correlation maps between box average SLA over the DaNS area and u10 (upper left), v10 (upper right), SST (lower left) and SLP (lower right). Statistical significance of the correlations has been

assessed on the basis of the Fisher z-transform. Crossed where nonsignificant at $95 \%$ confidence level

The correlation map with the v10 field nowhere yields correlations above 0.4 , and shows less spatial structure than the maps from $\mathrm{u} 10$ and SLP. The highest correlations are seen in the Atlantic Ocean off the west coast of Ireland and indicates that strong northward winds in the Atlantic lead to increasing levels of SLA in the DaNS. Meridional wind may be important because it's inherently coupled with the more dominant zonal wind component in the DaNS region. Indeed, prevailing winds drive cyclonic circulation within the North Sea basin which can lead to increased sea levels towards the DaNS area Dangendorf et al. (2014c). An alternative view is that an anticyclonic wind system with low pressure over the UK or a cyclonic system centred over Norway leads to wind set up in the DaNS. However, in light of the SLP correlation map and the DAC correction applied to the altimeter data which removes high frequency ( $<20$ days) atmospheric responses, this explanation is tenuous. It is more likely that the meridional winds are

correlated with SLA in the DaNS due to Ekman transport into the North Sea, implying that there is a remote forcing off the west UK coast.

Correlations with SST are quite low and attain a maximum near the DaNS area itself. Interestingly the pattern is rather consistent along the coast which could be in part related to upwelling/downwelling.

It is interesting that the correlation results presented here are in line with those found by Dangendorf et al. (2013) who performed a similar analysis using observations of sea level taken from the Cuxhaven tide gauge (situated to the south west of the DaNS region). In that study correlations were performed using data from 1871 to 2008. The consistency between the long term study at a fixed location and the work presented here with a spatial analysis over a shorter time span is a strong indicator of the stability in time between the local wind and local sea level in this region. 


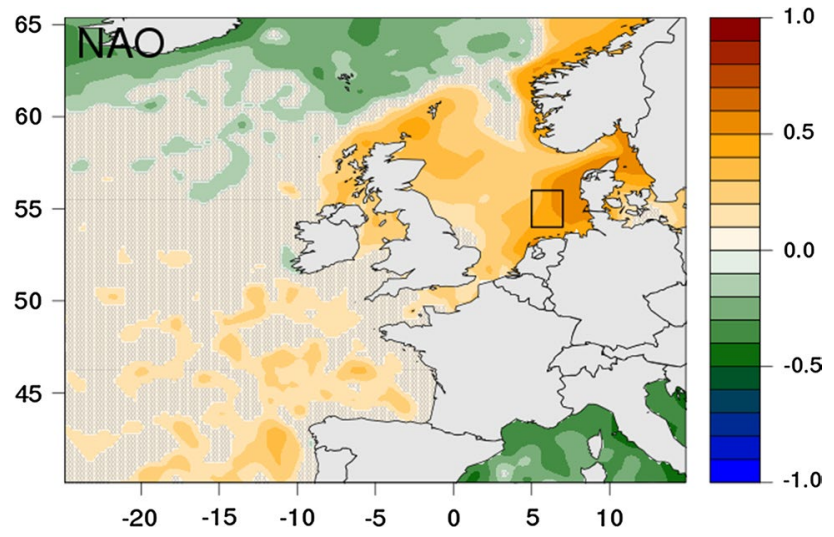

Fig. 4 Correlation maps between local SLA and NAO. Statistical significance of the correlations has been assessed on the basis of the Fisher z-transform. Crossed where non-significant at $95 \%$ confidence level

\subsection{Remote drivers}

We now look at remote drivers of SSV. The correlation pattern for the NAO is shown in Fig. 4. Whereas several studies have shown that highest correlations between the NAO index and the sea level in the North Sea occur at decadal time scales and in the winter months (e.g. Yan et al. 2004; Tsimplis and Shaw 2008; Chen et al. 2014) correlations using monthly data through all seasons also show a clear spatial structure. Highest positive correlations (around 0.6) with SLA are seen in the eastern parts of the North Sea, extending northwards off the coast of Norway. Negative values of up to -0.4 are found to the east of Iceland and in the Mediterranean. The NAO correlation map is broadly similar to those of SLP and u10 (Fig. 2), consistent with the findings from Dangendorf et al. (2013). This is not surprising as the NAO is defined as a pressure difference and the large-scale wind on monthly time-scales is geostrophically balanced.

\subsection{The DaNS area (2): identification of forcing mechanisms}

The similarity of the correlation patterns found between parameters in the previous section make it very clear that significant cross-correlations occur between the drivers. Here we focus on the DaNS area to examine this more fully. Table 2 shows the full cross-correlation matrix of SLA and the tested drivers for the DaNS area. Apart from the local drivers that have already been discussed, high correlations are found with NAO (0.48). However, the correlation between NAO and u10 is also high (0.54) which is consistent with an index based on atmospheric pressure differences and resulting wind patterns.

In the previous sections we presented a number of potential drivers of SSV in the NEA. The correlation coefficients between those and the SLA help to paint a picture which identifies the primary forcing mechanisms. u10 and SST show significant correlation with SLA and low cross correlations with other potential drivers. v10 is included for consistency with the wind being a vector rather than a scalar quantity. Table 1 shows that SLP has an insignificant local correlation with SLA in the DaNS area as expected. At this stage it is excluded from the LRM model. Climate indices are inherently representative of a number of higher level forcing mechanisms which act behind them and which in the ideal case we are seeking to identify. For example, the NAO affects wind, pressure and SST which means that a change in the NAO subsequently brings about corresponding baroclinic and barotropic responses from the ocean (Chen et al. 2014). We saw from Table 2 that there is a strong cross correlation between the NAO and u10 which suggests that much of the NAO signal can be captured using wind. Note that we will test this assumption with the VIF analysis in Sect. 6.4. The NAO is therefore also excluded from the LRM at this stage. u10, v10 and SST are thus identified from the simple physically motivated correlation analysis.
Table 2 (Cross-) correlation between tested local and remote forcing mechanisms for the DaNS area in the North Sea $\left(5^{\circ}-7^{\circ} \mathrm{E} 54^{\circ}-56^{\circ} \mathrm{N}\right)$ and SLA

\begin{tabular}{|l|l|l|l|l|l|l|l|l|l|}
\hline DaNS & SLA & $\mathrm{u} 10$ & $\mathrm{v} 10$ & UST & VST & WS & SST & SLP & NAO \\
\hline SLA & $\mathrm{X}$ & 0.84 & -0.13 & 0.84 & NS & 0.37 & 0.36 & NS & 0.48 \\
\hline \hline u10 & & $\mathrm{X}$ & $\mathrm{NS}$ & 0.95 & NS & 0.55 & 0.21 & -0.2 & 0.54 \\
\hline $\mathrm{v} 10$ & & & $\mathrm{X}$ & $\mathrm{NS}$ & 0.88 & NS & NS & -0.26 & 0.4 \\
\hline UST & & & & $\mathrm{X}$ & $\mathrm{NS}$ & 0.53 & 0.26 & -0.21 & 0.52 \\
\hline VST & & & & & $\mathrm{X}$ & 0.26 & 0.13 & -0.33 & 0.43 \\
\hline WS & & & & & & $\mathrm{X}$ & $\mathrm{NS}$ & -0.45 & 0.35 \\
\hline SST & & & & & & & $\mathrm{X}$ & NS & 0.17 \\
\hline SLP & & & & & & & & $\mathrm{X}$ & NS \\
\hline NAO & & & & & & & & & $\mathrm{X}$ \\
\hline
\end{tabular}

Figures in blue and red indicate values above an arbitrary value of 0.35 ; blue for correlation against SLA, red for cross-correlation with another driver

NS denotes not significant at the $95 \%$ confidence level 
In Sect. 2 we described an alternative method to identify relevant drivers by using VIFs. In this method VIFs are used to detect possible regressors that are well explained by linear combinations of other regressors. If the VIF-method is applied to DaNS area, SLP is added to the above list of relevant regressors, but excludes the NAO based on statistical significance. For this we have used a VIF threshold of 2. This means that a multiple LRM with SLP in addition to the other identified components, yields a strong increase in explained variance. In the next section we present results for both subsets of drivers, with and without SLP. We also explore the role of SLP as a descriptive parameter of SSV and seek to identify an underlying physical explanation for its apparent involvement in affecting SSV in the North Sea.

\section{Statistical modelling of regional SSV}

In this section we test the effect of the forcing mechanisms identified in Sect. 5.4 on driving SSV. A multiple LRM is used to test this hypothesis where we make the assumption that a good correlation between observed SLA and modelled SLA signifies a good capture of the SSV drivers. We also use explained variance which takes account of the amplitude of the variation between a parameter and the observed SLA.

We start with the inclusion of local wind (u10 and v10) and local SST in the LRM as these are the drivers identified by the simple correlation analysis with the highest correlation coefficients. We then test with SLP as an additional driver as identified from the VIF-optimised regressor selection method. As already explained in Sect. 2 the VIF-optimisation was carried out for the DaNS area and the same regressors are then used for the entire NEA domain for consistency.

\subsection{Reconstruction and explained variance}

The top panels in Fig. 5 show the correlation between the observed and the reconstructed SLA using the two sets of forcing parameters as regressors. Explained variance is given below. The general pattern seen in each panel is similar; highest correlations and explained variance are seen in the North Sea, extending from Denmark towards the entrance to the North Sea in the north west. Correlations greater than 0.5 appear to be confined to the relatively shallow waters (less than $300 \mathrm{~m}$ ) on the continental shelf. The suggestion that water depth plays a role in SSV is seen clearly near the Norwegian Trench where local water depths exceed $300 \mathrm{~m}$ and correlations are (strongly) reduced. Adding SLP as an additional regressor in the LRM, as motivated by the hierarchical VIF-selection, substantially increases the footprint size of high correlation and explained variance values in the North Sea, towards the east coast of the UK (right panel). The correlation between observed and modelled SLA in the DaNS area increases from 0.87 to 0.91 .

Figure 6 provides further detail for the VIF-based model. Since the VIF-based model explains more than $80 \%$ of the variance it comes as no surprise that the residual (left panel, vertical dashes) is much smaller than the observed SLA (red circles). The model captures the slow variations (5-year running averages) quite well. In fact, the VIF-based model provides a rather good estimate of the entire SLA distribution between the 5-th 95-quantile, as can be inferred from the quantile-quantile plot (right panel, red triangles) and only weakly underestimates the very low and high extremes.

It may seem obvious that the highest correlations are found for the DaNS area given that the parameters used in the LRM are selected based on our detailed analysis of the DaNS area; the LRM is effectively optimised for this region. Indeed the high SSV region in the open North Atlantic Ocean as identified in Fig. 1 (top-left) is not very well reconstructed with the parameters chosen here, implying that none of them can be classed as significant drivers of SSV in this region. The hot spots of high SSV in the English Channel have also not been reproduced as different forcing factors for SSV come in to play in a differing region, despite its relative proximity to the DaNS. In this case, the dominant process behind SSV in the DaNS region (u10) is not responsible for the SSV that seen in the English Channel.

\subsection{Regression patterns}

We now take a closer look at the regression coefficients that appear in the LRM (using drivers identified from the VIF regression for the DaNS area). High regression coefficients indicate a high sensitivity of SLA to the predictor. We scale these regression coefficients by their standard deviation so that they can be compared against each other. Figure 7 shows the regression coefficients and explained variance patterns (REVP).

The REVP of u10 shows a clear similarity to the spatial pattern visible in Fig. 5; a region of high explained variance exists off the west coast of Denmark. This indicates the high dominance that $\mathrm{u} 10$ has over the other regressors in explaining SSV in this region. The pattern for meridional wind is very different. High values are found northward from Spain and along the west of the UK (confined to the continental shelf) and the west of Norway. These results appear to be consistent with the findings of Calafat et al. (2012), Calafat and Chambers (2013) and Dangendorf et al. (2014a) who identify remote boundary wave forcing as a driver for SSV in this region brought about by changes in 

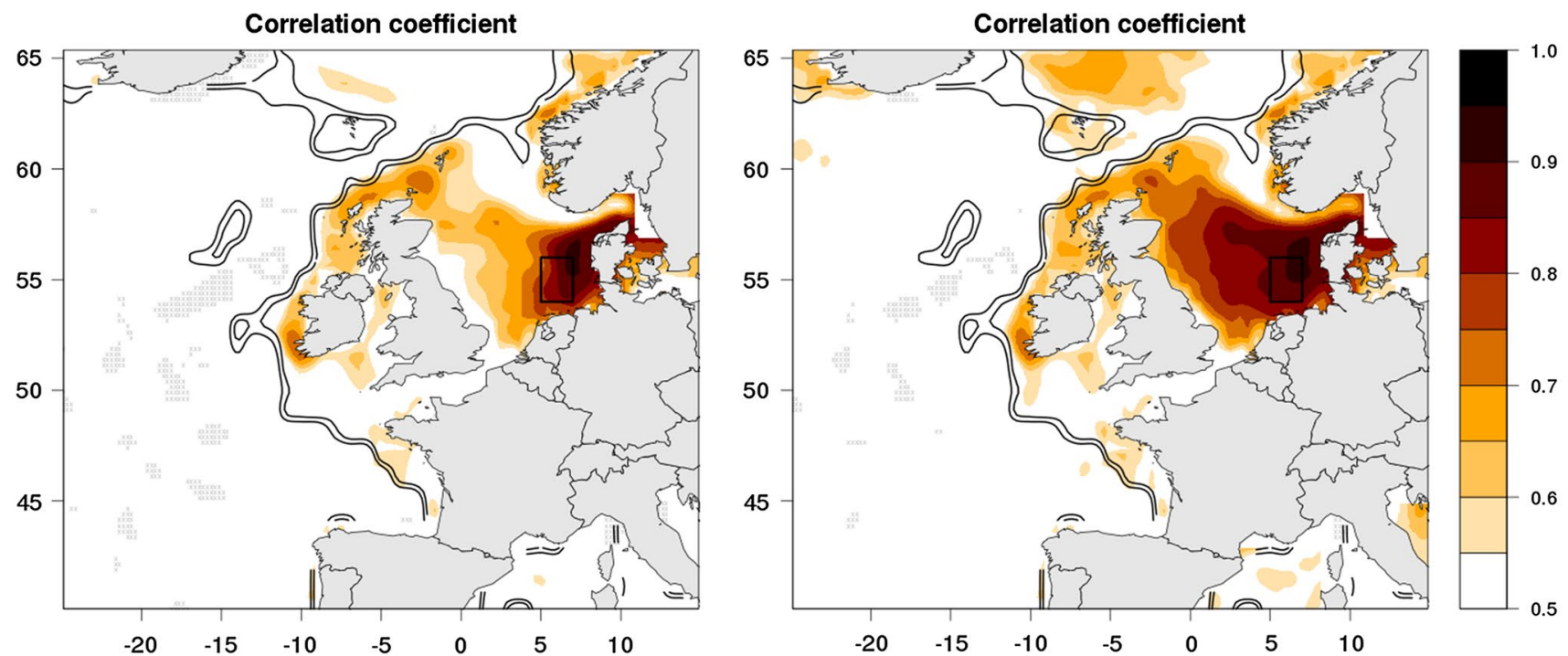

Explained Variance [\%]

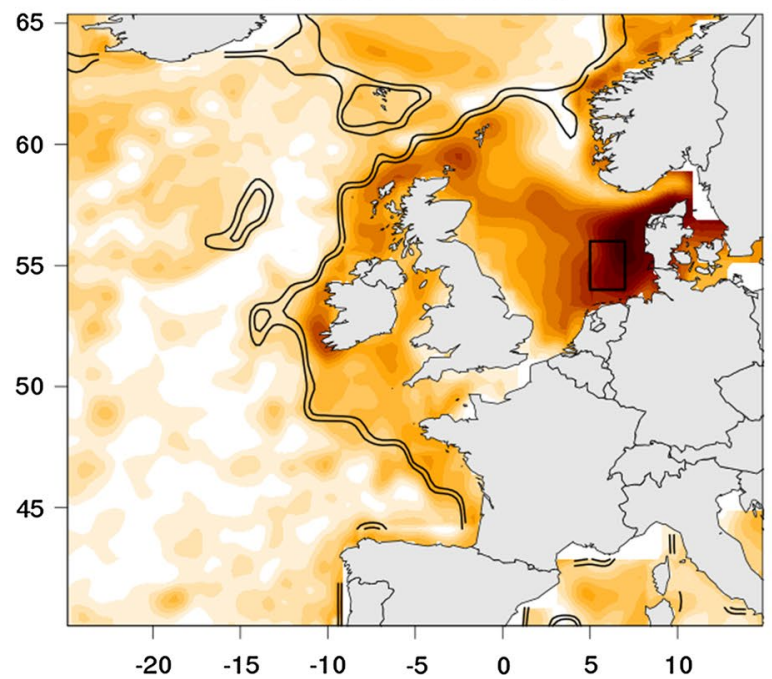

Explained Variance [\%]

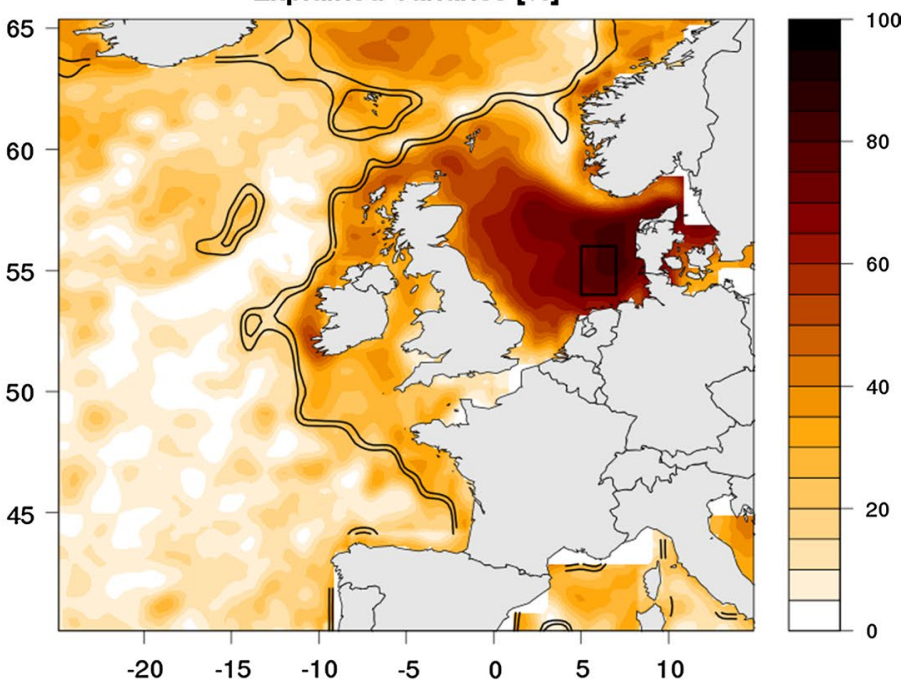

Fig. 5 Top Correlation maps between observed and reconstructed sea surface height over the period 1993-2013. Only correlations larger than 0.5 are coloured. Left (Local) u10, v10, and SST are included. Right SLP is also included. Explained variance is given beneath. Con-

tours show the 300 and $500 \mathrm{~m}$ bathymetry isolines. Statistical significance of the correlations has been assessed on the basis of the Fisher z-transform. Crossed where non-significant at $95 \%$ confidence level

v10 along the continental slope. Dangendorf et al. (2014a) further note that this forcing is not purely local because the propagation of the coastally trapped waves will affect SLA at all points along its path.

The REVP for SLP is positive throughout the North Sea and not relevant offshore from the continental shelf. SLP explains the variance of the SLA most strongly in a region off the east coast of the UK. Patterns for local SST is spatially rather uniform over the North Sea area with positive coefficients everywhere, implying higher SLA if the local SST is warmer, due to the thermal expansion of the mixed surface layer. Values for explained variance of are highest along the continental shelf, and to the north of Scotland.

\subsection{The remote effect of sea level pressure (SLP) on SSV}

As we noted earlier, Fig. 2 shows a significant correlation between SLP and SLA. Further, the VIF analysis identifies SLP as a descriptive parameter for SSV (Fig. 7) which appears to be at odds with Fig. 3 which shows that SLP has no local role on the observed sea level in the DaNS region. Assuming that the IB correction holds in the North Sea, the implication is that SLP may exert an effect on SLA through a remote mechanism. We therefore test here the remote forcing effect that SLP exerts on the SLA within the North Sea basin. 
Figure 8 shows correlation maps between SLP and the box average SLA for 3 additional locations in, and to the north of the North Sea basin (upper right, lower left and lower right respectively). In contrast to the DaNS region (upper left panel) we note significant correlation between SLP and SLA within these 3 regions. This points towards a physical process which is driven by SLP and exerts an effect which varies spatially.

In a meteorological setting, external surges can be generated by pressure systems passing the northern entrance region of the North Sea. However, this is not likely to be what we see here as this effect will have been removed from the SLA data through the DAC correction. Instead it is more likely that there is a remote influence of wind expressed in the SLP gradient. The spatial structure within the correlation maps for the boxes within the North Sea basin suggests an eastward wind pattern at the North Sea entrance. This would lead to Ekman transport directed into the North Sea, propagating along the UK coastline and increasing the sea level along the UK east coast. For the region outside of the basin (lower right panel) we see an inverted correlation pattern where this effect no longer holds.

The overall picture is that local eastward wind explains the variance of the SLA in the DaNS region, and to a lower degree, that remote eastward wind explains the variance towards the west of the North Sea basin. This regional dominance of a given parameter over another in the North Sea has previously been noted by Chen et al. (2014) and Dangendorf et al. (2014a). These results show that the VIF analysis is a useful tool in isolating descriptive parameters of SSV which can be used in LRMs if underlying physical processes can be identified.
Fig. 7 Regression coefficients and explained variance for the VIFoptimised LRM model for u10, v10, SLP and SST in the multiple regression model. Statistical significance of the correlations has been assessed on the basis of the Fisher z-transform. Crossed where nonsignificant at $95 \%$ confidence level

\subsection{VIF-optimised versus 'full' model: Does it make a difference?}

One question that comes to mind is whether, and if so how, can the LRM be extended? For example, does the correlation pattern between observed and reconstructed SLA change much if we include all regressors regardless of their possibly high VIF values and regardless of their cross-correlations. Figure 9 shows a representation of the monthly SLA time series for the DaNS area using (left) the VIFoptimised regressor selection, and (right) the 'full' model with all regressors stated in Sect. 2. Each row indicates the contribution from a particular regressor and oblique dashes are used to indicate VIF-excluded components and components that are found to be non-significant following a standard t-test. As one can see the full VIF model includes UST as well as u10. These parameters are known to covary and including both in a LRM model would not make sense. This provides confidence in the VIF optimisation process. (In fact the optimised VIF model selects VST in preference over v10; v10 is used in the LRM as it is coupled with u10 which is more dominant than UST.) Otherwise the differences between the approaches are marginal for the DaNS area. Those components that are excluded in the VIF-methodology are found to be non-significant in the 'full' model (right panel) which notably holds for the NAO.
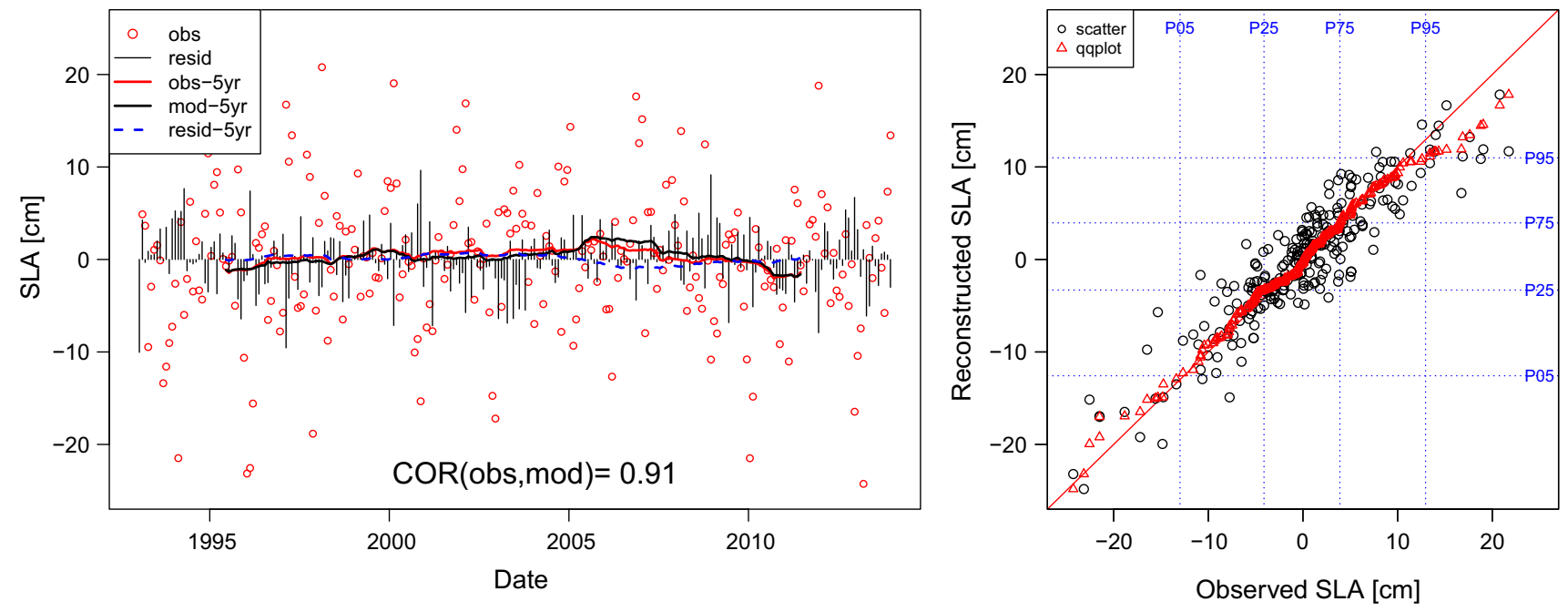

Fig. 6 Left Time series of the observed DaNS SLA (red circles) with vertical dashes indicating the residuals from the VIF-based model. Running-average values over 5 year periods as indicated by the leg- end are also shown. Right Scatter of observed and reconstructed DaNS SLA (black) and quantile-quantile plot (red), with lines indicating empirical quantiles (blue) 

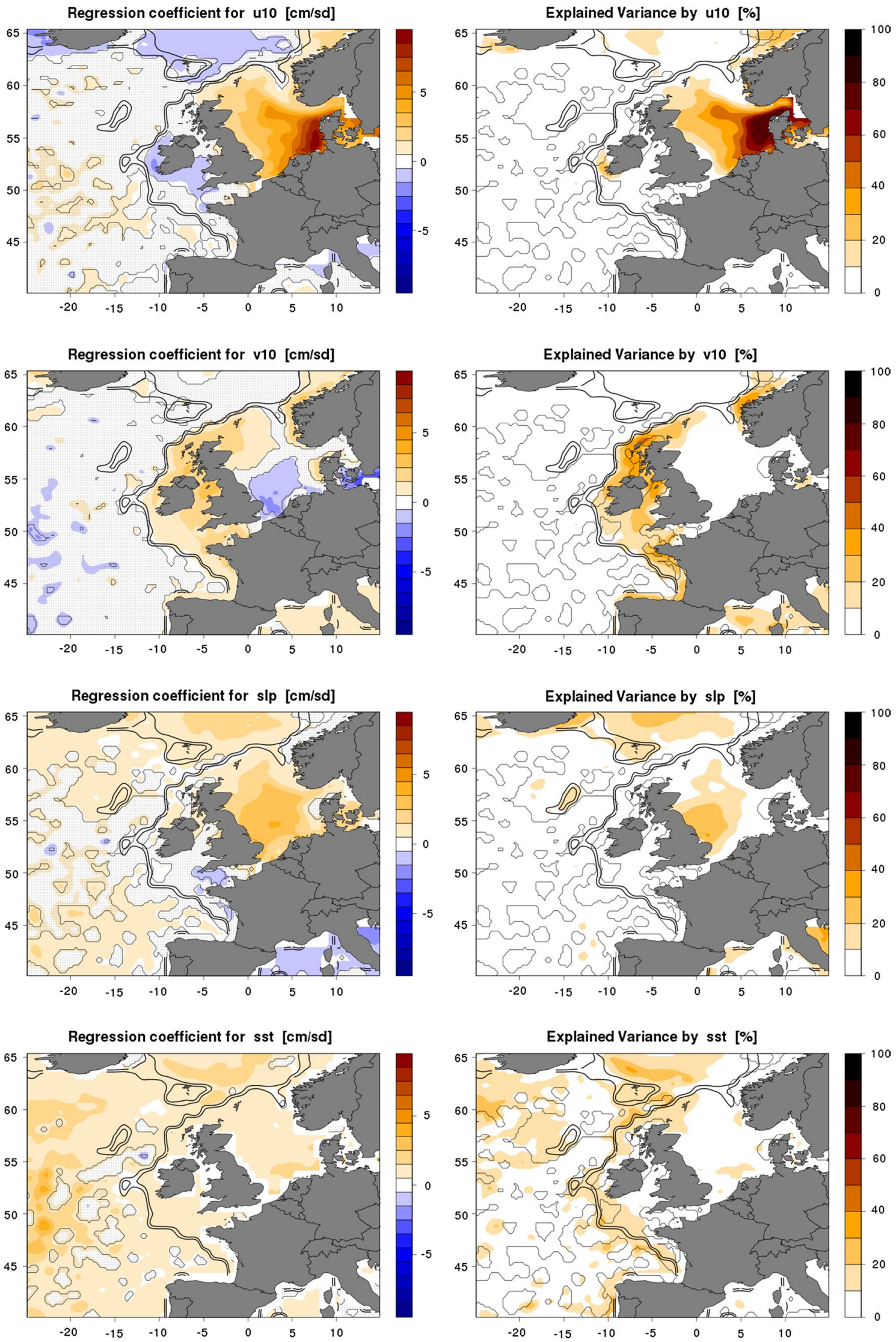

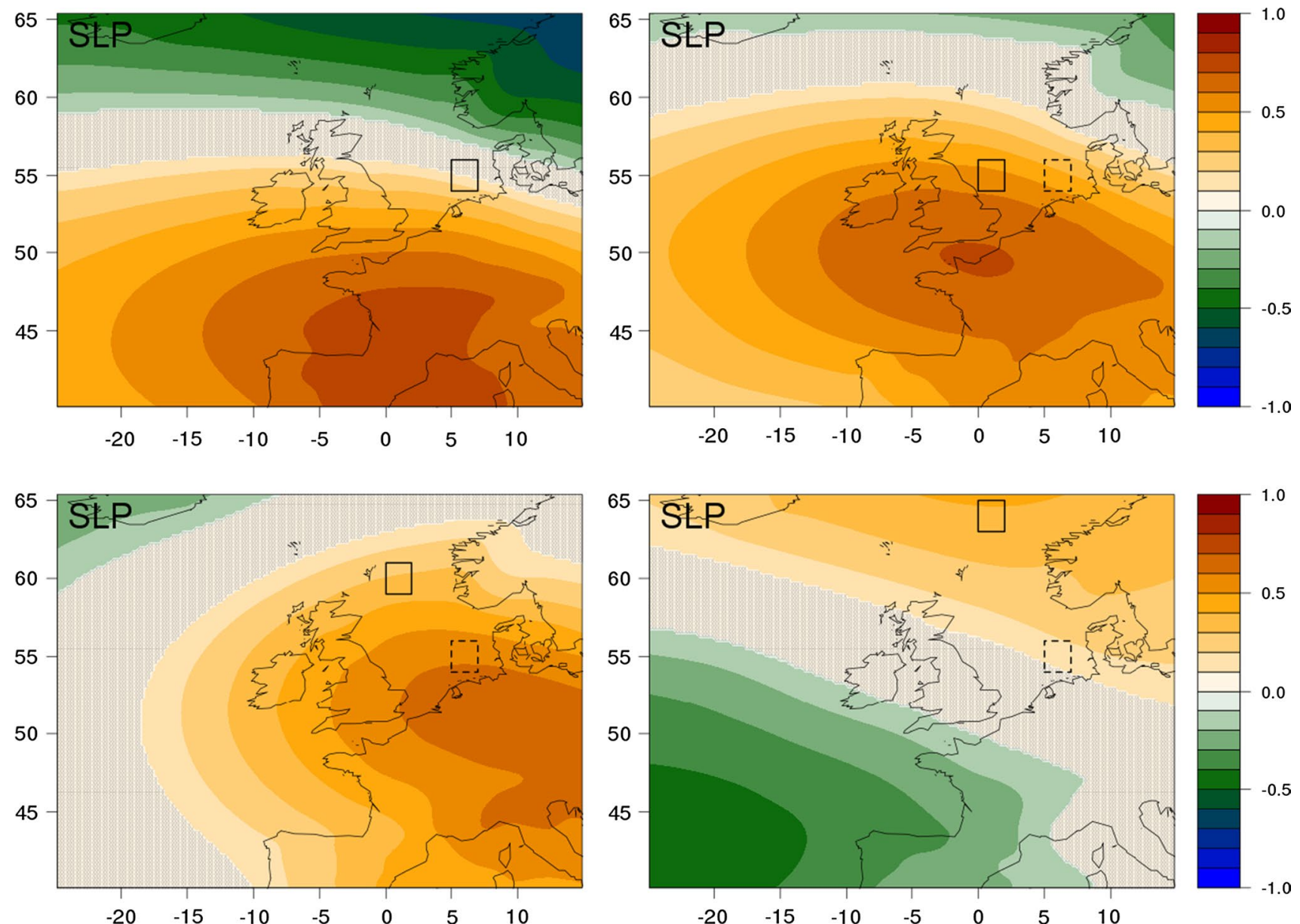

Fig. 8 Correlation maps between box average SLA and SLP for a number of locations in the North Sea (solid box). Figure 3 is repeated here for ease of comparison in upper left. Dotted boxes show location

of DaNS. Statistical significance of the correlations has been assessed on the basis of the Fisher z-transform. Crossed where non-significant at $95 \%$ confidence level
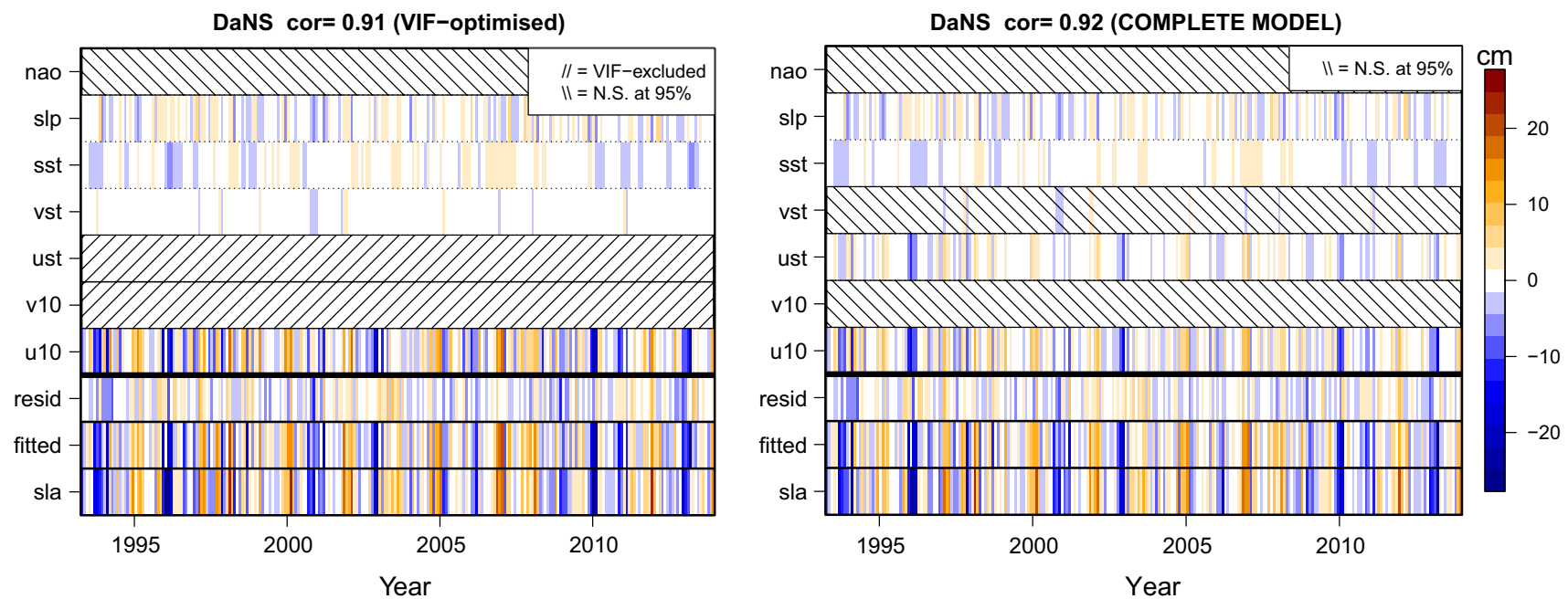

Fig. 9 Representation of the monthly SLA time series from VIF analysis for the DaNS area. VIF-optimised model (left) and full model (right). N.S. not significant 
The findings here therefore suggest that there are no additional parameters from our initial start point which can be used to improve the LRM. That's not to say that there are no further covarying parameters which can be used to describe the SSV in the DaNS region, and indeed we note that whilst the inclusion of more parameters may appear to increase the general performance of the LRM, it is done so at the risk of instability when using the model in a predictive capacity. We therefore assert that the LRM is valid only for the 21 year period in which the SLA and regressor data is present.

However, in order to test the robustness of the LRM we train it using the first third of the data and test it on the full data set. We find that there is no degradation of the result with correlation coefficients and explained variances are not significantly altered.

\subsection{Memory in the ocean: introducing autoregressive terms in the LRM}

Sea level anomalies are long-lived in the open ocean once they are excited (Hughes and Williams 2010). This means that a natural way in which the LRM can be extended is by including lagged SLA terms ("lag-1" and "lag-2") as additional regressors. In these cases the SLA information of the previous or 2 months is used to predict the SLA at month 0 . This provides information on how much of the signal can be understood from simple persistence in time. The inclusion of these auto-regressive terms has a huge impact on the correlation maps off the continental shelf. Figure 10 (upper panel) shows this correlation map where the VIF optimised model is used, but in addition the lag-1 and lag-2 month autocorrelations are included. The inclusion of these two terms does not change anything on the continental shelf but dramatically improves its accuracy in the open ocean. The regression coefficients (shown in the lower two panels) confirm that they play an important role in the regression. Whereas the lag-1 regression field is predominantly positive over the open ocean, the lag-2 field is much smaller and mostly negative, thus revealing a typical time-scale of 1-3 months for the eddying phenomena.

\section{Conclusions}

To increase our understanding of sea surface height variability (SSV) in the North East Atlantic we analyse monthly altimeter data. Particular focus has been on a region of high SSV off the Danish coast, referred to as the DaNS area. Variability in that region is high, as it is in a large part of the North Sea. Since the GMSL has been removed from the data and we also use linear detrending, our attention is turned towards variability in sub decadal time scales and not trending analyses.

The approach undertaken in this work to test and apply potential SSV forcing mechanisms in both the local and remote context has provided a spatial awareness of the processes which act across the region. We have identified a number of key drivers and have constructed a statistical model that is able to explain more than $80 \%$ of the variance in that region using information relating to local wind and SST conditions as well as atmospheric pressure which exerts a remote influence on the SLA through it's gradient and subsequent wind forcing. It appears unnecessary at these monthly time-scales to include information from large-scale drivers like the NAO which has been shown to be important in decadal scale SSV in the North Sea (e.g. Tsimplis and Shaw 2008; Chen et al. 2014), though it is noted that using seasonal or derivative indices such as $\mathrm{NAO}+, \mathrm{NAO}-$, RDG and GS as defined by Cassou et al. (2004) may increase the explained variance, especially during the winter months. Off the continental shelf, the statistical model performs rather poorly (correlations below 0.5 ), yet a powerful way to increase its performance is to include an auto-regressive term.

The LRM provides spatial information on the response of the North Sea to a number of parameters with underlying physical processes which describe the observed SSV in the DaNS area well, and confirms findings from previous studies. The importance of long shore winds in the North Sea basin found by tide gauge studies (Calafat et al. 2013; Dangendorf et al. 2013) is seen here with the areal data afforded by altimetry. The use of altimetry data here has also shown not only the linkage between a parameter and local SSV at a specific location, but also spatial patterns from which further inferences can be made relating to SSV over the model domain, for example, the role of SLP in forcing a non isosteric ocean response through Ekman pumping.

In addition to providing a spatial awareness of the local and remote factors affecting the SSV in the North Sea over the 21 years of observational data, the regression coefficients in the LRM show a stability over time; those derived from the first 6 years of data and applied to the complete 21 year data period lead to a modelled sea level which is not significantly different to the results presented here. This provides confidence in extending the model with either historical or forecast data. VIF analysis has been used to introduce a degree of objectivity in identifying parameters which can be used in the LRM, though these are subject to an insight and understanding of the underlying physical processes at work in them.

Although 'tuned' for the DaNS regions, the methodology used here is a general approach which can be extended and applied to other regions. The inclusion (or exclusion) of 

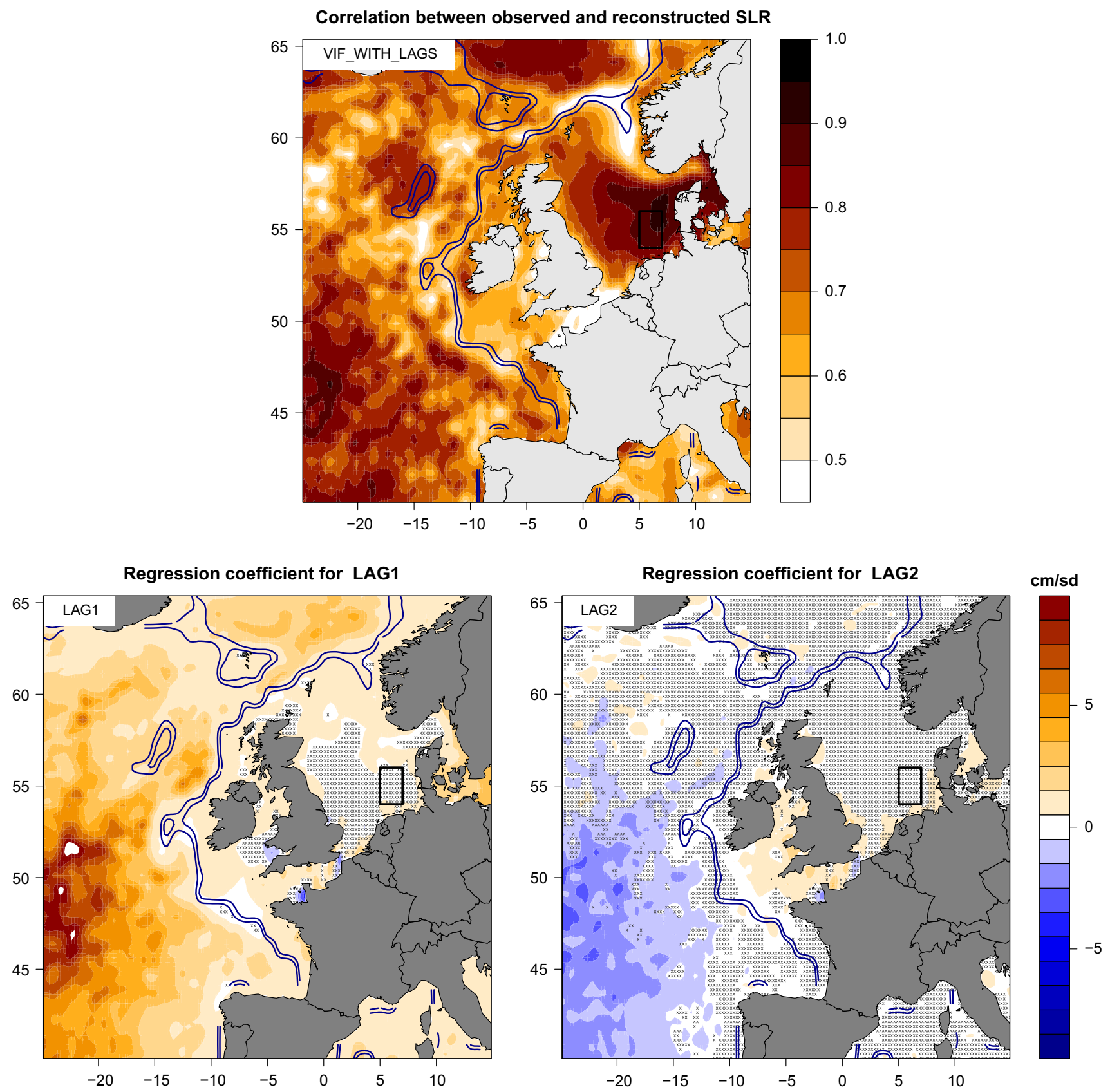

Fig. 10 Correlation between observed and reconstructed sea surface height over the period 1993-2013. Only correlations larger than 0.5 are coloured. Upper 'VIF optimised' model + lag-1 and lag-2 month SLA. Contours show the 300 and $500 \mathrm{~m}$ bathymetry isolines. Statistical significance of the correlations has been assessed on the basis of the Fisher z-transform. Crossed where non-significant at $95 \%$ confidence level. Bottom row patterns of the regression coefficients of the (left) lag-1 and (right) lag-2 SLA component used in the construction of the upper panel

time and shows potential for extension for longer periods, the model is based on data which is limited in duration to that of the satellite altimetry era. This means that only high frequency (i.e. sub decadal) forcing mechanisms can be identified. Further, the model is optimised for the DaNS region, with parameters identified as being most relevant here and applied throughout the model domain. The dominance of forcing 
parameters has been shown to vary over the region (for example, $\mathrm{u} 10$ is dominant in the east of the North Sea basin; SLP in the west) and this is manifest in magnitude of the local regression coefficients. For simplicity here, no account has been taken into regarding an entirely different selection of parameters to be used across the model and applied locally and we have focussed here on the DaNS region which exhibits the highest levels of SSV in the model domain.

Whilst local wind was shown to be a dominant driver of SSV in this region, no account is made that the response of the ocean to wind forcing is not purely local because information can be carried along the coast by boundary waves (Sturges and Douglas 2011; Calafat and Chambers 2013; Dangendorf et al. 2014a). Additionally we have not considered any explicit terms to account for mass-loss changes from glaciers and ice-sheets. As the time-series we have considered here are relatively short, the mass loss contributions which are approximately linear have been put 'silently' removed by linearly detrending the data. Neither have we explicitly included specific oceanic processes, such as ocean circulation, movement of transient features or Rossby wave propagation (Calafat and Chambers 2013).

We have carried out tests that augment the LRM with a 0-700 $\mathrm{m}$ heat content regressor, as could for example be obtained from the ECMWF ocean reanalysis ORAS4 model. However that ocean reanalysis product assimilates altimetric SLA (ECMWF 2015) so it was excluded for reasons of consistency. SST was found to be nearly as effective over the open ocean, and more effective over the continental shelf of the North Sea, which for most part is shallower than $70 \mathrm{~m}$. Additionally, tests using ESA CCI altimetry data showed no significantly different results to those obtained and presented here using AVISO altimetry. Further, tests with the inclusion of regressors which relate to deep ocean processes such as meridional heat transport did not improve the correlations over the open ocean. It appears that the ocean eddies become independent once they are shed by the Gulf Stream, as clearly demonstrated by the large correlations found if auto-regressive terms are retained in the LRM.

\begin{abstract}
Acknowledgments This work is part of the research programme "Nieuw Nederlands Polair Programma" which is (partly) financed by the Netherlands Organisation for Scientific Research (NWO). The authors gratefully received constructive comments from Richard Bintanja, Roderik van de Wal and Sönke Dangendorf. We are also thankful to two anonymous reviewers whose comments helped to improve an earlier version of this manuscript.
\end{abstract}

Open Access This article is distributed under the terms of the Creative Commons Attribution 4.0 International License (http://creativecommons.org/licenses/by/4.0/), which permits unrestricted use, distribution, and reproduction in any medium, provided you give appropriate credit to the original author(s) and the source, provide a link to the Creative Commons license, and indicate if changes were made.

\section{References}

AVISO (2014) SSALTO/DUACS user handbook: (M)SLA and (M) ADT near-real time and delayed time products CLS-DOSNT-06-034, 4.1. AVISO

Bilbao RAF, Gregory JM, Bouttes N (2015) Analysis of the regional pattern of sea level change due to ocean dynamics and density change for 1993-2099 in observations and cmip5 aogcms. Clim Dyn. doi:10.1007/s00382-015-2499-z

Calafat FM, Chambers DP (2013) Quantifying recent acceleration in sea level unrelated to internal climate variability. Geophys Res Lett 40(14):3661-3666. doi:10.1002/grl.50731

Calafat FM, Chambers DP, Tsimplis MN (2013) Inter-annual to decadal sea-level variability in the coastal zones of the Norwegian and Siberian Seas: the role of atmospheric forcing. J Geophys Res Oceans 118(3):1287-1301. doi:10.1002/jgrc.20106

Calafat FM, Chambers DP (2013) Quantifying recent acceleration in sea level unrelated to internal climate variability. Geophys Res Lett 40(14):3661-3666. doi:10.1002/grl.50731

Cassou C, Terray L, Hurrell JW, Deser C (2004) North Atlantic winter climate regimes: spatial asymmetry, stationarity with time, and oceanic forcing. J Clim 17(5):1055-1068. doi:10.1175/1520-0442(2004)017<1055:NAWCRS >2.0.CO;2

Cazenave A, Dieng H-B, Meyssignac B, von Schukmann K, Decharme B, Berthier E (2014) The rate of sea-level rise. Nat Clim Change 4:358-361. doi:10.1038/NCLIMATE2159

Chambers DP, Mehlhaff CA, Urban TJ, Fujii D, Nerem RS (2002) Low-frequency variations in global mean sea level: 1950-2000. J Geophys Res Oceans (1978-2012) 107(C4):1-1. doi:10.1029/ 2001JC001089

Chen X, Dangendorf S, Narayan N, O'Driscoll K, Tsimplis MN, Su J, Mayer B, Pohlmann T (2014) On sea level change in the North Sea influenced by the North Atlantic Oscillation: local and remote steric effects. Estuar Coast Shelf Sci 151:186-195. doi:10.1016/j.ecss.2014.10.009

Church JA, Clarke PU, Cazenave A, Gregory JM, Jevrejeva S, Levermann A, Merrifield MA, Milne GA, Nerem RS, Nunn PD, Payne AJ, Pfeffer WT, Stammer D, Unnikrishnan AS (2013) Sea level change. In: Climate Change 2013: the Physical Science Basis. Contribution of working group I contribution to the IPCC fifth assessment report

Church JA, White NJ (2006) A 20th century acceleration in global sea-level rise. Geophy Res Lett 33:L01602. doi:10.1029/200 5GL024826

Church JA, White NJ (2011) Sea-level rise from the late 19th to the early 21st century. Surv Geophys 32(4-5):585-602. doi:10.1007/ s10712-011-9119-1

CRU/UEA (2014) North Atlantic Oscillation (NAO). Retrieved from http://www.cru.uea.ac.uk/cru/data/nao/. Accessed 6 Aug 2014

Dangendorf S, Mudersbach C, Wahl T, Jensen J (2013) Characteristics of intra-, inter-annual and decadal sea-level variability and the role of meteorological forcing: the long record of Cuxhaven. Ocean Dyn 63(2-3):209-224. doi:10.1007/s10236-0130598-0

Dangendorf S, Calafat FM, Arns A, Wahl T, Haigh ID, Jensen J (2014a) Mean sea level variability in the North Sea: processes and implications. J Geophys Res Oceans. doi:10.1007/ s00382-013-1932-4

Dangendorf S, Rybski D, Mudersbach C, Müller A, Kaufmann E, Zorita E, Jensen J (2014b) Evidence for long-term memory in sea level. Geophys Res Lett. doi:10.1002/2014GL060538

Dangendorf S, Wahl T, Nilson E, Klein B, Jensen J (2014c) A new atmospheric proxy for sea level variability in the southeastern North Sea: observations and future ensemble projections. Clim Dyn 43(1-2):447-467. doi:10.1007/s00382-013-1932-4 
de Ronde JG, Baart F, Katsman CA., Vuik V (2014). Zeespiegelmonitor. Kenmerk 1208712-000-ZKS-0010

Dee DP, Uppala SM, Simmons AJ, Berrisford P, Poli P, Kobayashi S, Andrae U, Balmaseda MA, Balsamo G, Bauer P et al (2011) The ERA-interim reanalysis: configuration and performance of the data assimilation system. Q J R Meteorol Soc 137(656):553-597

ECMWF (2015). Ocean reanalysis. Retrieved from http://www. ecmwf.int/en/research/climate-reanalysis/ocean-reanalysis. Accessed 20 May 2015

Frankcombe LM, McGregor S, England MH (2014) Robustness of the modes of indo-pacific sea level variability. Clim Dyn. doi:10.1007/s00382-014-2377-0

Gornitz V, Lebedeff S, Hansen J (1982) Global sea level trend in the past century. Science 215(4540):1611-1614

Haigh ID, Wahl T, Rohling EJ, Price RM, Pattiaratchi CB, Calafat FM, Dangendorf S (2014) Timescales for detecting a significant acceleration in sea level rise. Nat Commun. doi:10.1038/ ncomms 4635

Hughes CW, Meredith MP (2006) Coherent sea-level fluctuations along the global continental slope. Philos Trans R Soc Lond A Math Phys Eng Sci 364(1841):885-901. doi:10.1098/ rsta.2006.1744

Hughes CW, Meredith MP (2006) Coherent sea-level fluctuations along the global continental slope. Philos Trans R Soc Lond A Math Phys Eng Sci 364(1841):885-901. doi:10.1098/ rsta.2006.1744

Katsman CA, Hazeleger W, Drijfhout SS, van Oldenborgh GJ, Burgers G (2008) Climate scenarios of sea level rise for the northeast Atlantic Ocean: a study including the effects of ocean dynamics and gravity changes induced by ice melt. Clim Change 91:351374. doi:10.1007/s10584-008-9442-9
Marcos M, Tsimplis MN (2007) Forcing of coastal sea level rise patterns in the North Atlantic and the Mediterranean Sea. Geophys Res Lett. doi:10.1029/2007GL030641

NOAA/OAR/ESRL PSD (2015). ICOADS 2 degree. Retrieved from http://www.esrl.noaa.gov/psd/data/gridded/data.coads.2deg.html. Accessed 29 July 2015

Richter K, Nilsen JE, Drange H (2012) Contributions to sea level variability along the Norwegian coast for 1960-2010. J Geophys Res Oceans (1978-2012). doi:10.1029/2011JC007826

Slangen A, Carson M, Katsman C, van de Wal R, Kohl A, Vermeersen L, Stammer D (2014) Projecting twenty-first century regional sea-level changes. Clim Change 124(1-2):317-332

Sturges W, Douglas BC (2011) Wind effects on estimates of sea level rise. J Geophys Res Oceans (1978-2012). doi:10.1029/201 0JC006492

Tsimplis MN, Shaw AGP (2008) The forcing of mean sea level variability around Europe. Global Planet Change 63(2):196-202. doi:10.1016/j.gloplacha.2007.08.018

Wakelin SL, Woodworth PL, Flather RA, Williams JA (2003) Sealevel dependence on the nao over the NW European continental shelf. Geophys Res Lett. doi:10.2029/2003GL017041

Woodworth PL, Pouvreau N, Wöppelmann G (2010) The gyre-scale circulation of the North Atlantic and sea level at Brest. Ocean Sci 6(1):185-190. doi:10.5194/os-6-185-2010

Woolf DK, Shaw AGP, Tsimplis MN (2003) The influence of the North Atlantic Oscillation on sea-level variability in the North Atlantic region. Global Atmos Ocean Syst 9(4):145-167

Yan Z, Tsimplis MN, Woolf D (2004) Analysis of the relationship between the North Atlantic Oscillation and sea-level changes in northwest Europe. Int J Climatol 24(6):743-758. doi:10.1002/ joc. 1035 